\title{
Small Firms, the Informal Sector, and the Devil's Deal
}

By

Judith Tendler

Everybody loves small firms. Whether big donors or small, bilateral or multilateral. Whether left or right, government or non-government, practitioners or academics, myself included. Small firms have even gained a prestigious place in the firmament of social policy, where microcredit and other small-firm programs are seen as forming a safety net into which the poor can gently fall. But this is exactly where the trouble begins, and that's what this article is about.

Over the last decade or so, myriad programs, projects, and policy reforms have focused attention on informal-sector firms (IS) and small firms (SF) in general, as part of a broader social-policy agenda of reducing poverty and unemployment. ${ }^{2}$ Despite this welcome attention, many planners in developing countries nevertheless continue to view SF/IS programs as "only" welfare, rather than the stuff of "serious" economic development. The particular form taken by SF/IS support in many countries reinforces this view, as explained below, as does the way SF/IS support is often embedded in politics. This jeopardises certain benefits, ironically, that we hold crucial to the current agenda of reducing poverty and unemployment: greater observance by firms of environmental and labour regulations, sustained increases in efficiency and productivity in local economies and, as a result, improvement in the quantity and quality of jobs.

I was first struck with the darker side of small-firm and informat sector support when interviewing economic-development officials in the Brazilian state of Pernambuco. I was curious to 
know why they had not included, in a new program of support to a handful of small-firm clusters in the state, a particularly vibrant and longstanding garment cluster about a two-hour drive from the capital city. They explained that it would be quite awkward to elevate to "growth-pole" status a cluster of firms that was notorious for not paying taxes and not observing other government regulations. ${ }^{3}$ At the same time, however, they did not see themselves as having the option to enforce these regulations, even as a quid pro quo for providing public support, because the cluster was concentrated in two municipalities that contained more than 30,000 electors.

After visiting some other places and reading about cases in other countries, I came to interpret what I was observing as a kind of unspoken deal between politicians and their constituents-myriad small-firm owners, many in the informal sector. If you vote for me, according to this exchange, I won't collect taxes from you; I won't make you comply with other tax, environmental, or labour regulations; and I will keep the police and inspectors from harassing you. I call this tacit understanding "the devil's deal" because it causes informality to become more attractive, and formalisation less attractive, than they otherwise might be. Once the deal is made, it is difficult for either side to get out of it, as the above-mentioned comments of the Brazilian officials reveal.

In certain ways, then, the devil's deal can pose just as significant a barrier to formalisation and upgrading of small-firm clusters ${ }^{4}$ as the actual costs themselves of formalisation and regulation. Much of the policy advice on this subject, however, focuses on the "burdens" themselves as the source of the problem-particularly, the costs of formalising and observing tax, environmental, and labour codes. It advocates reforms, in turn, that grant special relief from these burdens to small firms in the form of 
exemptions from or reductions of taxes and other costs associated with environmental and labour regulation. In addition, the small firm literature is strangely silent on the politics in which support to small firms is so firmly embedded. ${ }^{5}$

The dynamic of the devil's deal also reinforces the distinctly dismissive attitudes held by many development planners and by development-bank managers toward smaller and informalsector (IS) firms. To the extent that these managers and civil servants acknowledge the importance of SF/IS assistance, they often view it as a "welfare" measure that belongs in "social" rather than economic development agencies - in ministries or departments of labour or social welfare, or special small-firm agencies. In their eyes, support to small firms will help mop up the unemployment resulting from the necessary reforms and initiatives meant to restructure the economy and institutions of government for a world of liberalised trade.

In these terms, the small firm sector becomes mainly an instrument for preserving and even creating jobs - albeit often poor-quality jobs in poor quality firms - rather than as an opportunity to stimulate economic development. This frees policymakers to dedicate their economic-development attention elsewhere, by reducing for them the political cost of the job losses that ensue from the modernisation of industry and economic-policy reforms. From this perspective, and more generally, small firm assistance programs do the important work of helping to maintain the "social peace," rather than helping to modernise the local economy. ${ }^{6}$ Contributing to this same perspective, many international donors and non-government organisations couch their current support for IS/SF assistance, such as micro-credit and other programs, in terms of "safety-net" measures for poverty reduction. 
The "devil's deal" offers more to IS/SF clusters than just disregard of their violation of regulations. Governments often grant small firms a particular kind of support in which there is something for everyone - special lines of cheap credit, blanket credit amnesties when times are bad, and blanket exemptions for small firms from certain taxes and regulations. The exemptions are "burden-relieving" in that they reduce the small firms' costs (or keep them from increasing) in a way that requires no effort on their part. They are also "universalist" or "distributive" in that they benefit all small firms-whether they want to grow or not, whether they are seeking to improve their efficiency or not, and regardless of sector.

In maximising the number of satisfied constituents, this kind of support to small firms is ideal for maintaining and increasing electoral loyalty. It is less than ideal, however, for stimulating local economic development that is sustained and employment-enhancing. Today, that is, the most widely agreed-upon forms of effective public support for local economic development do not have this universalist and burden-relieving character. In some ways, in fact, they are just the opposite. They strategically identify and try to remove bottlenecks to improved efficiency, productivity, and marketing for the sector as a whole. Before any significant support is rendered, they often require or elicit broad involvement of the sector in a process of discovering exactly what the problem is and what to do about it. And they may benefit directly - at least at first - only those firms most capable and most interested in upgrading their production, which, in turn, often leads to their formalisation. The histories of dynamic small-firm clusters often reveal this particular kind of strategic public support which, in turn, has been central to the formation of strong local economies and the reduction of unemployment.

Once the "devil's deal" has been made between firms and politicians, it becomes politically 
awkward for governments to carry out the above-mentioned strategic and sector-specific support because it does not automatically benefit all small firms. To the extent that it does benefit the region as a whole - as in the breaking of important infrastructure bottlenecks or the linking of local producers to outside buyers through trade fairs - the benefits may be longer in coming and more diffuse, and their effects may be felt by many firms only indirectly. These traits are just the opposite of those characterising the relief provided by the burden-reducing exemptions and subsidies - immediate, automatic, universal, conspicuous, and directly available to each firm as an individual unit.

Classifying firms by their size (small, medium, or large) for purposes of public policy, rather than by their product or sector, reinforces the tendencies toward the burden-reducing approach. "Small," that is, can encompass a quite diverse set of firms - rustic and sophisticated, producing in different sectors, and located in different places. For purposes of lobbying for burden-reducing measures, for example, "small" can even be include both a rustic brick-making operation in the countryside and a sophisticated software firm in the city. With such heterogeneity, the only way an association can serve a majority of its members is to appeal to the broadest common denominator - namely, size. But the kind of support that best fits the size denominator is the burden-reducing subsidies and exemptions because of, as seen above, their universal and distributive benefits. That is why we often find small-firm associations pressing more for the universalist exemptions than for the strategic supports. In this sense, then, size is also the lowest common denominator, in that its associated subsidies and exemptions are the least likely to lead to sustained development.

No one would deny the importance of small-firm associationalism in the histories of many dynamic industrial clusters. Organising and lobbying according to firm size, moreover, may be the only 
way small firms can hope to compete with larger and more powerful firms for the attention of policymakers. At the same time, the attention paid by governments and donors to firms according to their (small) size - and to small-firm associationalism - can also work inadvertently in the same direction as the devil's deal.

The large volume of research on small firms and their clusters does not tell us much about the circumstances under which universalist concerns and demands will dominate strategic ones in small-firm associations, let alone the sequence by which universalist concerns and their burden-relieving support sometimes miraculously give way to more strategic episodes. Complicating the story, the two approaches may coexist within the same association. ${ }^{7}$ Putting together and lobbying for a strategic agenda, moreover, requires harder work over a longer period of time - more deliberation, analysis, and consensus - than lobbying for the burden-reducing exemptions and subsidies. In this sense, the universalist exemptions of the devil's deal will be more appealing to small-firm associations because they are easier, just as they are more appealing to politicians because of their greater political yield.

Focusing on the difficulties small and informal firms face in meeting the costs of environmental and labour standards distracts our attention from pursuing opportunities for firms to, indeed, rise to the occasion and meet these standards, rather than be exempt from them. Though we are used to thinking that small firms need protection from these "excessively" burdensome costs, there are many cases in which they have actually met those costs and, contrary to the burden-relieving scenario, have been better off for it. They became more efficient, produced higher quality goods, and gained new access to more demanding markets. 
How did such dynamic clusters get from where they were before - when they were the pathetic, low-productivity small firms of the welfare scenario - to where they are today? Much of the research on small-firm clusters fails to ask this particular question, dedicated as the research has been to understanding how these clusters function at any particular moment in time or drawing best-practice lessons for practitioners. It is the evolutionary sequence of these cluster histories, however, that will reveal lessons on how to promote small-firm dynamism while not compromising - in contrast to the burden-reducing approach - our concerns for increasing the rule of law, reducing environmental problems, protecting worker rights, and upskilling labour. The histories will also provide insights into the sequences of events and other circumstances under which local actors make the transition from burdenrelieving to more strategic and transformative deeds.

Offhand, five recent cases come to my mind of major advances in improving the efficiency, productivity, and other sector-wide aspects of partly small-firm clusters in which standards were increased rather than waived. In three of these cases, the advances were triggered in part by suddenlyimposed bans of importing countries on a developing country's export. Germany banned the import of leather goods produced with certain chemicals, all used by the Tamil Nadu leather-goods cluster in India; the U.S. banned the import of precision surgical instruments from Pakistan, made in the Sialkhot cluster, because of problems with the quality of steel; and El Salvador banned the import of Nicaraguan cheese because it did not meet the importing country's new hygienic standards. ${ }^{8}$ In each of these cases, the importing country had been a major buyer of the product for some time. The producers, acting through previously existing collective, public, and public-private institutions, rose to the occasion meeting the costs of the new standards, resuming exporting, and becoming more competitive. One 
would not want to count on such wrenching import bans, of course, as a "best practice" for upgrading small-firm clusters.

The remaining two examples did not need the import bans by customer countries to fuel them, and hence show another possible path to similar results. These two cases were also triggered by problems in the international market - namely, increasing competition to small-firm clusters caused by the entry of cheaper or better products into the international market from other countries. One case involved a footwear cluster in southern Brazil and the other, a marble cluster in Andalucian Spain. ${ }^{9}$

In both these cases, importantly, the small-firm associations first lobbied government for the typical burden-reducing measures - tax exemptions, credit amnesties and subsidies. But, unusually, the government explicitly rejected the burden-reducing approach as a way of coping with the crisis provoked by the outside competition. Making its own counter-demand, the government agency involved offered a different kind of deal in exchange for support: it required that the firms gather together and engage in a time-consuming and difficult exercise that identified problems and proposed sector-specific solutions.

In the Andalucian case, the marble cluster had declined through the years partly because of increasing competition in the international market from the Italian marble industry. The Planning Ministry offered the following deal: the firms would themselves have to get together, decide what the problems were and how they might be overcome, and then arrive at a proposal on what to do. In addition, the Ministry required $100 \%$ consensus among the sector's firms, in return for which it offered technical and facilitating assistance for this process, and the promise of financing for whatever proposal for upgrading 
that might emerge. This was a deal also, then, but in certain ways it was just the opposite of the devil's deal: what it demanded in return was not political loyalty, but a set of behaviours that would lead to greater economic dynamism.

In the Brazilian case, similarly, the association of footwear producers - faced with a crushing increase in cheap footwear imports in the late 1990s - lobbied the state government of Rio Grande do Sul for tax relief. The government denied the burden-reducing relief, but proposed a different kind of exchange. It offered to finance and assist in other ways the participation of these firms in an important major trade fair, an annual event held in the shoe-producing Franca region of Brazil, so as to increase their exposure to the large Brazilian market. As a result, their sales increased significantly, which also increased the state's sales-tax return by more than the amount expended for this support.

The Brazilian story also shows that such strategic deals can yield political returns as robust as those of the burden-reducing measures. The state's footwear cluster, located a few hours from the capital city in the Sinos Valley, had typically voted against the party that was in power at the time of this offer - the left-wing Workers' Party. Many of the smaller firms who benefited from the trade-fair experience, however, subsequently shifted their allegiance to that party, in a first-time split of the political loyalties of the footwear-producing sector as a whole.

Obviously, not all small-firm clusters would be able to respond as successfully as happened in these cases. But the general sympathy in the SF/IS agenda for protecting small firms as a group from various burdens - often in the name of protecting the "only" source of employment in particular local economies - distracts our attention from possibilities among such firms to meet these costs in a way that leaves them and the local economy better off. Such an economically robust outcome might provide 
more sustained employment, let alone better environmental and labour standards and tax collection, than would protecting small firms as a category.

I am arguing, then, that the widespread sympathy for small firms as a special category - and in particular their "inability" to pay taxes and conform to environmental and labour standards - tends to undermine other important concerns about appropriate strategies for reducing poverty, increasing employment and development, and improving governance. These include reducing environmental degradation (to which small-firm clusters can be major contributors); protecting worker rights to organise, and improving health and safety in the workplace; expanding the coverage of social security, health, and other social insurance to poorer workers; increasing the tax yield of governments so as to better finance public services and, in so doing, drawing government and firms together in a contract - in this case, to promote a more inclusive style of economic development.

Researchers and funding institutions could contribute to breaking the stranglehold of the devil's deal by exploring the paths by which SF/IS firms or sectors actually grew into formality, treated workers better and upgraded their skills, and worked toward improving their environmental practices. These kinds of cases - where firm agglomerations succeeded in meeting regulatory requirements, became more competitive, and were better off for it - need to be sought out and chronicled, such that lessons for policy can be learned from them. This would help to show policymakers - particularly at the subnational level, where such enforcement and economic-development support increasingly takes place - another path and another set of possibilities. Showing that such outcomes are perfectly imaginable, and familiarising planners with the felicitous outcomes of actual cases and the paths that led to them, might also contribute toward reducing the generalised antipathy in the economic-development sector of 
many countries toward the enactment or enforcement of environmental and labour standards.

The policy sympathy for small firms as a category of assistance, in sum, is desirable on many grounds. At the same time, the concern about protecting small firms from reasonable regulations - let alone from the vicissitudes of the market - can become toxic when combined with the political dynamics of the devil's deal. The waiving of tax, labour, and environmental regulations that results from sympathy for the "plight" of small firms may hinder rather than help local economies if it condemns them to lowlevel economic stagnation, degradation of the environment, and violation of worker rights. The latter all clearly increase unemployment and poverty, as well as burdening unnecessarily the task of povertyreducing social policy. 


\section{Endnotes}

1. This note was developed from Section 3 of my chapter, "Why social policy is condemned to a residual category of safety nets, and what to do about it: thoughts on a research agenda for UNRISD," in the forthcoming volume, Social Policy in a Development Context, edited by Thandika Mkandawire (copies of the chapter can be obtained from tendler@mit.edu). I thank UNRISD for supporting the larger paper, and for helpful comments on an earlier draft at a seminar on the topic of social policy that it sponsored in Sweden. For comments on this or previous drafts, I thank Mansueto Almeida, Éverton Chaves Correia, Alberto Criscuolo, Jacob Lima, Nichola Lowe, Mick Moore, Lisa Peattie, Lant Pritchett, Rémy Prud'homme, and Hubert Schmitz, as well as participants in seminars sponsored by the Institute of Development Studies at Sussex, Cornell University, Duke University, the Harvard Center for Population and Development Studies, the World Bank, and the Brazilian Center of Analysis and Planning (CEBRAP) in São Paulo. Support for part of the research contributing to this article is gratefully acknowledged from the Brazilian Bank of the Northeast (BN), through the MIT/BN project.

2. By specifying the subject to be firms that are small and/or informal, I am not excluding from the universe of firms discussed herein some small firms that are partly or fully formal, and even some firms that are producing in the same sector and in the same locality as the small firms, but tending toward medium size. Though this fuzzy definition ignores important distinctions, it is necessary to reflect the fact that SF demands often emerge from a set of firms defined by the space they occupy together and the same product or value-chain in which they produce. Just as important, the loose definition serves the purpose of brevity, and is also consistent with the language used by the international development community in describing and justifying the kinds of policy objectives and programs discussed in this article.

3. The non-payment of taxes in this region has been no secret in Brazil. A national news magazine reported — in an article on the dynamism of the cluster entitled, "Taxes not paid here" - that "this 
[cluster] wouldn't even exist if firm owners had to pay taxes." The chief of the state's Treasury Department, in turn, said that the taxes collected there did "not even represent $1 \%$ of what could be collected." "Aqui não se paga imposto: conheça Santa Cruz do Capibaribe, a cidade que se transformou numa das mecas da informalidade no brasil [Taxes not paid here: welcome to Santa Cruz do Capibaribe, the city that transformed itself into one of the meccas of informality in Brazil]," José Maria Furtado, Revista Exame [Brazil], Vol 35, Edition 733, No. 3, pp. 96-99, 7 February 2001. [Translations from the Portuguese are mine.]

4. With apologies to today's cluster specialists, I will use the word "cluster" throughout more loosely than it is sometimes defined, partly for lack of a better single word and to avoid the more ponderous "agglomeration." In its more carefully-defined form, a small-firm "cluster" usually means a set of small firms located close together geographically with significant inter-firm relations among them, with an atleast evolving associational dynamic, and usually some history of success in growing, and in improving efficiency and productivity; in more recent definitions, other parts of the supply chain to which those firms belong also have to be present to qualify as a "cluster." My less demanding use of the term requires only that a particular region has a significant number of small firms producing the same product or in the same value chain, which may also include an admixture of medium and even large firms. Again, my sloppier definition is in some ways more consistent with the way the term is used in the world of policy and practice.

5. There are some exceptions, though they tend to come from outside the small-firm literature, involving country studies by political scientists; some take place in the now-industrialised countries. For example, one study that actually narrates an analogous deal between government and informal firms is John Cross' Informal Politics: Street Vendors and the State in Mexico City (Stanford, California: Stanford University Press, 1998). Cross documents how continued informality, in this case, was central to the government's willingness to support the vendors' organising efforts, and to negotiate a series of their demands. In a study of taxation in Zambia, Lise Rakner notes that the government "may have refrained from broadening its tax base to include the emerging informal business sector in order not to 
jeopardise its support among the Owambo-speaking majority; "The Politics of Revenue Mobilisation: Explaining Continuity in Namibian Tax Policies," Forum for Development Studies (No.1, June 2001, p. 142). Italian political scientists studying Italy's postwar period have pointed explicitly to the importance of " $[\mathrm{c}]$ lientelist generosity - in the form of regulation to protect small business, a lax approach to tax collection for the self-employed, and so on - was systematically directed at these groups"; see Jonathan Hopkin and Alfio Mastropaolo, "From patronage to clientelism: comparing the Italian and Spanish experiences," Chapter 7 in Clientelism, Interests, and Democratic Representation: the European Experience in Historical and Comparative Perspective, edited by Simona Piattoni (Cambridge: Cambridge University Press, 2001). Suzanne Berger's work on this same subject in Italy and France is cited in the following note, \#6. For an interpretation of small-firm politics in the U.S. economy as affecting viewpoints and policies, see Charles Brown, James Hamilton, and James Medoff, Employers Large and Small (Cambridge, MA: Harvard University Press, 1990).

6. Using the small-firm sector to maintain employment and the social peace is not unique to the current period, or to less-developed countries. In work on the political economy of industrial policy in France and Italy, published more than 20 years ago, the political scientist Suzanne Berger explicitly linked the small firm programs and regulations that developed in France and Italy during the 1970s to the simultaneous pursuit of a large-firm industrialisation strategy by those very same governments. She had posed the question of why two countries that had so explicitly pursued a large-firm modernisation industrial policy could at the same time have enacted such pro-small firm legislation and assistance. It is from her work that I take the term, "keeping the social peace." See, "The Uses of the Traditional Sector in Italy: Why Declining Classes Survive," in: The Petite Bourgeoisie, edited by Frank Bechafer and Brian Elliot, pp. 71-89 (New York: Saint Martin's Press, 1981); and "The Traditional Sector in France and Italy," in: Dualism and Discontinuity in Industrial Societies, edited by Suzanne Berger and Michael Piore (Cambridge: Cambridge University Press, 1980),Chapter 4, pp. 88-131.

7. I thank Nichola Lowe for pointing out these possibilities to me - on the basis of a case from Jalisco state in Mexico; see "Trainers by Design: Small Firm Upgrading and Inter-Firm Learning in Jalisco, 
Mexico," Ph.D. dissertation, Department of Urban Studies and Planning, Massachusetts Institute of Technology, 2002 (forthcoming).

8. For the German/Indian case, see Poonam Pillai, "The state and collective action: successful adjustment of the Tamil Nadu leather clusters to German environmental standards," Master's Thesis, Department of Urban Studies and Planning, M.I.T., 2000; for the U.S./Pakistan case, see Khalid Nadvi, "Collective Efficiency and Collective Failure: The response of the Sialkot surgical instrument cluster to global quality pressures," World Development (27, no. 9:1605-1626, 1999); and for El Salvador, see a forthcoming study by Paola Pérez-Alemán, "Decentralized Production, Organization and Institutional Transformations: Large and Small Firm Networks in Chile and Nicaragua," Paper presented at the Third Meeting of the Institute for Latin American and Iberian Studies, Columbia University, International Working Group on Subnational Economic Governance in Latin America from a Comparative International Perspective, San Juan, Puerto Rico, 25-28 August 2000. Note that, in the U.S./Pakistan case, Nadvi reports that there was more cross-cluster success in improving the quality of the precision steel than with respect to labour and environmental standards.

9. For the Andalucian case, see Michael Barzelay (2000), "Managing Local Development: Lessons from Spain.” Policy Sciences 24 (3 August):271-290; for the Brazilian case, I thank Luiz Miranda of the Economics Department of the Federal University of Rio Grande do Sul. 